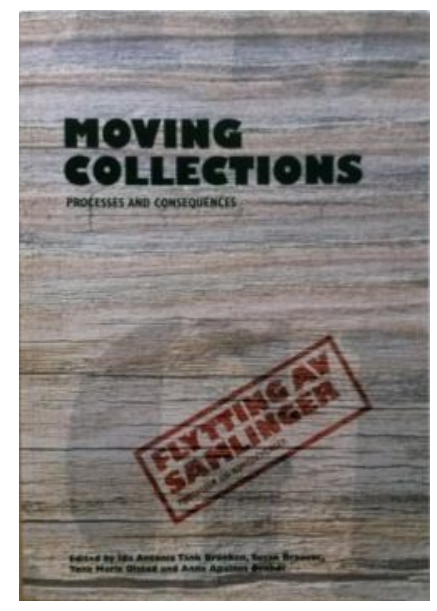

\title{
Moving Collections. Processes and Consequences Flytting av samlinger. Prosesser og Konsekvenser
}

Editado por Ida Antonia Tank Bronken, Susan Braovac, Tone Marie Oistad and Anne Apalnes Ørnhøi.

Publicado por Archetype Publications Ltd in association with NKF-N (Nordisk Konservator Forbuind-Norge). London, 2012.

220 páginas, $297 \times 210 \mathrm{~mm}$.

ISBN: 978-1-904982-84-5

Este texto recoge las contribuciones ( 24 comunicaciones y 8 posters) presentadas en la conferencia "Planing to move? Processes and consecuences for collections, objects and society", organizada por la sección Noruega de la Nordic Conservator Association, del grupo Nórdico del IIC, que tuvo lugar entre los días 15 y 17 de octubre de 2012, en Oslo.

Dado el lugar de celebración del evento y que la organización corrió a cargo de la sección Noruega del IIC, poco más de la mitad de las comunicaciones son en inglés, mientras que el resto están escritas en noruego, con abstacts en inglés (algunos muy reducidos), lo que en la práctica limita nuestra capacidad de comprensión.

El objeto de la conferencia fue el transporte de objetos y obras de arte. Esta es una de las tareas que está adquiriendo mayor importancia en la vida de los museos e instituciones que albergan colecciones. Continuamente se mueven piezas para renovar y mejorar las formas de gestionar su exhibición, almacenamiento, estudio o tratamiento. Pero el interés sobre este tema es de máxima actualidad dada la necesidad que tienen algunas instituciones de planificar en la próxima década el traslado de una parte importante o el total de sus colecciones.

Uno de los intereses centrales de la reunión era conocer experiencias actuales que describieran tanto los retos como las soluciones aplicadas en campos como la logística, los estándares de embalaje o los sistemas de control. Se presentaron ejemplos concretos de trabajos de investigación y casos prácticos que cubren el movimiento de los más variados objetos, a todas las escalas.

El continuo desarrollo de los museos y el crecimiento de las colecciones implican la búsqueda de soluciones temporales o definitivas para el almacenamiento de las nuevas obras, para la adaptación a los nuevos modelos expositivos o a los nuevos servicios requeridos. Esto obliga a planificar movimientos complejos por la naturaleza de las piezas involucradas, su número y dimensiones. Obliga a trabajar conjuntamente y a coordinar equipos compuestos por especialistas de distintas disciplinas y también, en muchos casos, a tomar decisiones en cierto modo pragmáticas, asumiendo los riesgos y las limitaciones que impone la realidad. 
Las comunicaciones presentan una gama muy variada de necesidades y enfoques, en función de las dimensiones de los museos, de la naturaleza de sus colecciones y de las características y de las posibilidades de cada institución. En este sentido hay referencias a traslados masivos de obras como en el caso del Museo Nacional de Arte, Arquitectura y Diseño de Oslo; del Museo de Bellas Artes de Boston; del Museo Victoria and Albert de Londres; del Museo de Arte Popular de Lisboa o del Museo Nacional de Islandia en Reikiavik. También se describen movimientos de colecciones más pequeñas como la del Museo Munch de Oslo; del Museo de la Cultura Mundial de Gotemburgo; la colección de registros sonoros de la Universidad de Kansas o la sección de fotografía del Museo de la Ciudad de Estocolmo. A otra escala se presentan los traslados del barco vikingo más grande del mundo, durante una exposición itinerante o el desmontaje, tratamiento y la recolocación de una instalación del artista finlandés Antero Ruotsalainen, por ejemplo.

Salvo tres comunicaciones que desarrollan investigaciones sobre factores de deterioro o estándares de manipulación y transporte, en general todos los trabajos presentados tratan casos particulares. En unos se pone el acento en la unificación de servicios de almacenamiento, sistemas registro, gestión y control, entre varios museos de pequeñas dimensiones. En otros ejemplos se centran en resolver retos específicos como el movimiento y la reubicación de obras durante los trabajos de ampliación de un museo o la adaptación de edificios industriales para el almacenamiento y exhibición de objetos.

Precisamente hay que destacar, como uno de los puntos fuertes de esta publicación, la abundancia de casos prácticos diferentes, pero marcando siempre la importancia de la calidad del trabajo llevado a cabo, tanto en la planificación como en la realización práctica de los traslados, ya se trate del movimiento de un elemento aislado como de una colección completa.

En el lado negativo, hay que mencionar que una parte importante de los textos están escritos en noruego. Esta es una cuestión de cierta importancia que pone en evidencia la cada vez mayor necesidad de publicar en un idioma de uso internacional, si queremos que la información llegue de forma global a la comunidad profesional y científica.

Emilio Ruiz de Arcaute Diputación Foral de Álava 